\title{
Novel Corona Virus and Its Mechanism
}

\author{
Shubham Singh Yadav ${ }^{1}$, Dr. Swaroopa Chakole ${ }^{2}$ \\ ${ }^{1}$ Intern, Dept. of Community Medicine, Jawaharlal Nehru Medical College, Datta Meghe Institute of Medical \\ Sciences (Deemed to be University), Sawangi (Meghe), Wardha-442001, Maharashtra, India \\ ${ }^{2}$ Professor, Dept. of Community Medicine, Jawaharlal Nehru Medical College, DattaMeghe Institute of Medical \\ Sciences (Deemed to be University), Sawangi (Meghe), Wardha-442001, Maharashtra, India \\ Email: ${ }^{1}$ yadav191296@gmail.com, ${ }^{2}$ drswaroopachakole@gmail.com
}

Corresponding author's name and address: Dr. Swaroopa Chakole, Department of Community Medicine, Acharya Vinoba Bhave Rural Hospital, Datta Meghe Institute of Medical Sciences (DU).

Corresponding author's email id: drswaroopachakole@gmail.com

Type of Article: Review

Conflict of Interest: None

Funding: DMIMS

Ethical Approval: IEC, DMIMS, Wardha.

\begin{abstract}
BACKGROUND

COVID-19 is creating ruckus in almost entire part of the globe and needs to be tackled at mission mode. SUMMARY

COVID-19 has been proven lethal and deadly and in order to tackle the spread, study is needed to understand the virus behavior. Pathophysiology of the virus is extremely crucial as the uncertain nature of the coronavirus is creating hurdles in mitigating measures. Supposedly long-term implication which are bound to happen in several infection cases needs proper attention

\section{CONCLUSION}

Prevention is always better than cure and it is true especially in case of COVID-19 pandemic as there are long term implications are attached. Necessary infrastructure needs to be made available so that these increasing numbers demand should be catered. Non-coercive measures prove best results and social vaccine of mitigation measures is already available to ensure the prohibition of the viral spread. More study is need so that long term implications of COVID-19 is established with the necessary empirical data.
\end{abstract}

KEYWORD: COVID-19, CORONAVIRUS, SARS-COV-2, LONG COVID-19.

\section{INTRODUCTION}

The infamy of taking more than two million lives in a short span of a year is attached to the coronavirus disease 2019 or COVID-19. The unprecedented nature of the pandemic and the highly virulent behavior along with extremely lethal capacity has already been registered. Almost every aspect of the human life has been adversely affected by the COVID-19 which is caused by novel coronavirus or SARS-COV-2. This coronavirus has struck the world previously but with limited reach in the form of severe acute respiratory syndrome and Middle Eastern respiratory syndrome. As of January 22,
2021, 97,629,138 people are reportedly infected by COVID-19 from

all across the world and 2,093,725 people lost their lives due to related medical complications(1). The spread was so fast that on March 11, 2020, World Health Organization (WHO) declared the COVID-19 as pandemic upgrading the status from public health emergency of international concern (PHEIC)(2). The devastation is so huge that no other event was able to do such adverse impact as COVID-19 did in almost past hundred years. United States of America, India, Brazil, Russian Federation, United Kingdom and France are the worst affected countries accounting for almost half the 
cases and case fatalities linked to COVID19(3). The novel coronavirus id the successor of SARS-COV which caused the SARS epidemic. Many similarities can be seen in both the outbreaks. Although the extent of the COVID-19 is far and wide than SARS. The novel coronavirus is inactive outside the body and needs a host to activate itself as it does not contain DNA(4). It contains only RNA and contains spike proteins. The host cell is then hijacked for the growth of the virus and then it multiplies rapidly spreading to other parts of the body. Symptoms are various and also contributes to the uncertainty of the virus behavior. Long term implications are also attached and it therefore important to prevent the disease from happening with the help of available mitigation measures.

\section{NOVEL CORONAVIRUS AND ITS MECHANISM}

Novel coronavirus is the main culprit behind the current pandemic situation. The novel coronavirus as the name suggest is the newest member in the coronaviridae family. Other notorious members of the coronaviridae family are SARS-COV which caused the 2003 severe acute respiratory syndrome (SARS) and MERSCOV which caused the 2012 Middle Eastern respiratory syndrome (MERS)(5). Both these past outbreaks were confined to certain geographical area and the case numbers were low due to the same reason(6). But the case fatality rate was 10 percent and 35 percent respectively which is far lesser than COVID-19 case fatality rate. But the whole number which is affected by the COVID-19 is so huge that no other natural or medical calamity or event was happened in past hundred years which is comparable to this event. The devastation was so huge that world was at standstill for some days which was never experienced in almost past few decades. Coronavirus got its name from the shape of the virus observed under the electron microscope. A crown shaped structure along with spikes of proteins gave it the name of coronavirus. Corona is another word for crown. The scientific name given by taxonomical authority is severe acute respiratory syndrome coronavirus 2 (SARS-COV-2). Because it has considerable number of similarities with the SARS-COV hence it is called as successor of SARS-COV.

Coronaviruses are not new to the human civilization. In fact, they were discovered as early as 1960's when particular type of unknown flu was affecting many numbers of people. That year, then coronavirus was first identifying. But the virus was almost harmless and found in every person's nasal sample in Europe where it was first reported. The worst-case scenario associated with that virus was cold and flu which was easily controllable. Many people harbored the virus without even knowing it. Even today many types of coronaviruses are still inhabiting the human nasal passage. There were no such casualty cases reported due to the previous virus infection. But the viruses are notorious for mutating themselves and producing varied clinical outcomes in patients. This was first felt in 2003 outbreak of severe acute respiratory syndrome (SARS) where massive number of case infections and casualties were reported first time due to coronavirus strain. 8098 registered case infections of the SARS were reported of which 878 resulted in fatal clinical outcomes making the case fatality rate to stand at around 10 percent. Then the study and research on coronaviruses got accelerated and various observations were carried out to assess the coronavirus in detail. Another such outbreak in 2012 known as Middle Eastern respiratory syndrome (MERS) got erupted and there too, many casualties were reported. 1621 MERS infection were reported from around gulf countries and 584 of them develop severe clinical outcomes which led to deaths. The case 
fatality rate touched 35 percent which was huge. But these two major outbreaks caused by coronavirus was thankfully confined to a certain geographical regions and the spread was not global(7).

The single stranded ribonucleic acid (RNA) genomic virus is of size 26 to 32 kilobases. The coronaviridae family contains four genera. It includes alpha coronavirus (AlphaCOV), beta coronavirus (BetaCOV), gamma coronavirus (GammaCOV) and delta coronavirus (DeltaCOV). Mostly rodents like mouse and other similar creatures and nocturnal creatures like bats are thought to have reservoir of coronavirus. These viruses basically affect the respiratory tracts of the birds and mammals which includes human being. Bats are the most notorious reservoir of these coronaviruses and the event from transmission of the virus from one species to another via another intermediate species is call spillover effect. This spill over effect in case of novel coronavirus or SARS-COV-2 was supposedly happened in wet market of Wuhan city of the Hubei province in China. Wet market basically deals in live selling of various exotic species which are normally prohibited to eat as their habitat is quite isolates. The novel coronavirus supposedly jumped from the bats to pangolin which is highly traded animal for various illegal purposes(8). Then from pangolin it got spilled over to humans. The patients zero which is the first patient is supposed to be infected from animals indicating the zoonotic nature of the disease. Pangolin and snakes which are both part of diet in several Asian countries particularly china showed considerable amount of similarity when tested for coronavirus strain. The human-to-human transmission aspect took a while to be confirmed and this delayed the closure of the flights to and from the Wuhan which is the origin of the coronavirus. As far as the structure of the virus is concerned it shared approximately 89 percent of the structure with SARS-COV that is its predecessor. The novel coronavirus mainly contains BetaCOV genus among three other genera of the coronavirus. The mechanism of the coronavirus is not changed much and it still uses the angiotensin enzyme 2 receptors to enter the host cell. The angiotensinenzymes 2 or ACE 2 receptors are present on very crucial organs like cardiovascular system's heart, lung if respiratory system. The ACE 2 receptors are notorious for providing the gateway for the novel coronavirus to enter the cell. The SARS-COV-2 have spike proteins which helps them to get attached to the ACE 2 receptors and then they enter the cell. The control of the cell then is fully transferred to the coronavirus and then the coronavirus expands rapidly multiplying manifold. This can be extremely dangerous as the novel coronavirus is creating medical complications in human anatomy. The model used in the mitigation and the containment of the coronavirus is the test, trace and treat model. The testing part which is used to diagnose the patients with COVID-19 is the first part in the containment procedure. Various tests are there to find out that a person is infected by COVID-19 or not. Reverse transcript polymerase chain reaction(RT-PCR) test is so far considered as golden standard and it is the final diagnostic procedure which result is considered as ultimate and then necessary process is started. It contains the reverse transcription of the ribonucleic acid (RNA) of the coronavirus and then it is amplified till the critical threshold (ct) is hit. The less is the ct value the more is the viral load in a person concerned. For sampling, nasal swabs are taken along with throat swabs for accurate results. Generally, the results are shown in few hours to a day. Rapid antibody test is also available but is used to check the prevalence of the disease in a particular area. The results from such random testing may help in curating targeted containment efforts which will be more efficient. Many 
other tests are also available including point of contact test which produces results in just minutes. These are mostly employed in industries and workplace so that before starting to work a person may be know their infection status so that they do not contribute to the further transmission. Transmission of the coronavirus is the main concern and matter of problem as the highly virulent virus needs extremely harsh approach to contain it. The case numbers nearing to ninetymillion mark is the indication of the same. Also transmission through fecal to oral route has been accepted as many random samples taken from sludge coming out from containment zones and hospitals were tested positive for the virus(9).

\section{CLINICAL MANIFESTATION}

Clinical manifestation of the virus is extremely varied from age groups to geographical regions. But the initiation of the disease shows some common symptoms such as cold, cough and fever. Asymptomatic and pre symptomatic patients do not even show these symptoms but can possibly transmit the virus from them to others. From these flulikesymptoms, it aggravates to other symptoms. Especially in case of comorbid patients where they are already suffering from various diseases, and having immunosuppressive state making ground fertile for virus's growth. The uncertain nature of the virus can be seen from its changing symptoms.(10) Initially it started from cough, cold and fever then it goes to diarrhea and loss of taste and smell. Acute respiratory distress syndrome (ARDS) and pneumonia are most common among patients developing fatal outcomes. Hypoxemia, dyspnea can be shown by certain group of patients. Persons with better immune system and healthy lifestyle does not develop the severe symptoms in most cases and does not even know if they got the infection or not. But the vulnerable groups such as comorbid patients, old aged patents, pregnant women, children's and infants are more vulnerable as they are going through their immune suppressive state(11). The need of the critical like intensive critical care unit is more for these groups. The case fatality rate overall is between one to two percent and the case fatality rate between the age group of 60 and above is as high as 25 percent which is a serious cause of concern. Also, the frontline fighters in fight against the COVID-19 such as law enforcement agencies, doctors and nurses along with allied health workers are more vulnerable. In fact, according to International Nurses Council, more nurses had died during the duty against the COVID-19 than in the First World War. Numerous doctors had also laid their life in the process of containment of the menace spread by novel coronavirus. Proper mitigation tools such as mask and personal and protective kits (PPE) must be provided to ensure the safeguarding of the corona warriors. The guidelines issued by World Health Organization (WHO) and various other competent health care agencies must be followed in order to safeguard oneself from the virus(12).

\section{CONDITION OF LONG COVID-19}

Few daysago, it was assumed that the treatment part after the diagnosis is the essential and important part and then the person infected is free to live its pre COVID-19 life. He or she need not worry about anything and they can be back to work gain with the same vigor and efficiency as they were working few months ago. But several studies and reports are telling the harsher truth that one might not want to listen especially the infected persons. Severalpatients, post discharge from the treatment of the COVID-19 has reported persistence of some symptoms which they never experience. Patients recently treated from COVID-19 reportedly registered symptoms like extreme fatigue, occasional 
dyspnea, intermittent loss of taste and smell, brain fogging which is basically confusion while deciding anything and so on. In addition to that reduced physical capacity was one of them which was common to almost all the patients. This is definitely a cause of concern as till now only the treatment part of the COVID-19 was considered as difficult and after that there was nothing to worry(13). Clinical analysis of the patients revealed some more impairments which are supposedly brought about by coronavirus disease 2019. Weakening of the cardiovascular muscles, inflammation in alveolar tissues, renal impairment, muscle weakness and many more impairments were found to be there which were nonexistent before COVID-19 infection. The diffusion level of the oxygen and carbon dioxide from and to body has been affected adversely and thereby affecting the functioning of the body. Normal infected patients were taken aback by these symptoms but the researchers and doctors were anticipating these conditions as previous outbreaks of severe acute respiratory syndrome (SARS) and Middle eastern respiratory syndrome (MERS) shown some similar long-term implications of these coronavirus causing diseases. Follow up of several patients till twenty-four months was done and found out that only 29 percent of the health care professionals affected by the SARS were able to resume their work. That means rest of the health care professionals were unable to join the duty. Physical capacity reduction and anxiety and depression was another symptom were also been seen as long treatment isolation and then knowledge of reduction in physical capacity disheartened the infected patients which took considerable amount of time to recover. As the COVID-19 is progressing and more cases will arise of complaint about long term implications, the necessary infrastructure and adequate professionals must be reserved in order to cater the oncoming demand. Dedicated community health officer along with mental health expert must be appointed to take out the patient from depression and anxiety induced by the COVID-19(14).

\section{PREVENTIVE MEASURES}

The unprecedented nature of the pandemic and its extreme virulent nature has shaken the world through its core. NO one anticipated such medical calamity which never happened in almost past hundred years of the history of human civilization. Such is the impact of the coronavirus that whole world was at stand still for several weeks which was truly anunprecedented event. More than two million people lost their lives due to COVID-19 complications, the figure which never seen by human civilization in a particular year. All aspect of the human life has been affected(15-17). Therefore, it is important to protect oneself from disease infection which is highly fatal. Also, the longtermimplications are also providing compelling reason for adopting preventive measures to protect oneself as these implications take a huge toll on the wellbeing of the person. Several preventive measures are suggested by the WHO and other health acre agencies such as wearing of masks, physical distancing, and usingpersonal and protective equipment and so on(18-20). These measures are needed to be followed without any hesitancy as its efficacy has been seen in previous outbreaks. Weakening of immunity is the main reason which make an individual more vulnerable. Therefore, by focusing on building immunity, one can increase the chance of not getting the infection. Various foods and substances along with supplements which are proven to be immunity boosting. Vitamin C, Vitamin D, probiotics are meant to be beneficial in building immunity and maintaining the body metabolism at healthy levels. Vitamin $\mathrm{C}$ is generally known as antiinflammatory and anti-oxidants and known 
to remove toxins from the human body(2123). Exactly the same thing is needed as coronavirus induces inflammation on various tissues of the body. Vitamin D which can be absorbed from the sun and which in turn helps in absorbing the calcium from the food is also found to be useful in generating useful immunity response in case of external pathogenic invasion. Probiotics are the supplements which are used now a days to full fill the need of the good bacteria in gut. Without this bacterium the metabolism is not maintained at healthy levels and thus affects the immune response. The gut lung axis is proven already and should be maintained accordingly. This practice may also be useful in infected patients as their diet can be curated to these accommodatethese helpful substances and multiplier effect can be seen along with medications. Changing the lifestyle pattern for the betterment of the wellbeing of the body by exercising and practicing yoga and meditation will also benefit in increasing the chance of not getting thecoronavirus infection. Staying indoors when there is no necessity of going out and not loitering on the streets will make one more secure as one is away from the crowded places where infection can originate(24-27).

\section{CONCLUSION}

Novel coronavirus has wreaked too much havoc and it is the time to rebuild as the vaccine rollout drive are almost about to start. But it will take time to obtain the efficacy of the vaccine results on larger masses and how effective is the vaccine in containing the viral spread. Meanwhile coronavirus is about to stay for more time therefore we need to adapt with the virus and learn to live with the virus. Economic activities must be opened with proper care and preventive measures so that workers and professionals are safeguarded. Still no sure shot treatment is not available and therefore it is important to protect oneself from the exposure of the coronavirus. Prevention is always better than cure and it is true especially in case of COVID-19 pandemic as there are long term implications are attached. Necessary infrastructure needs to be made available so that these increasing numbers demand should be catered. Non-coercive measures prove best results and social vaccine of mitigation measures is already available to ensure the prohibition of the viral spread.

\section{REFERENCES}

[1] COVID-19 Map [Internet]. Johns Hopkins Coronavirus Resource Center. [cited 2021 Jan 22]. Available from: https://coronavirus.jhu.edu/map.html

[2] WHO Director-General's opening remarks at the media briefing on COVID-19 - 11 March 2020.pdf.

[3] WHO Coronavirus Disease (COVID19) Dashboard [Internet]. [cited 2021 Jan 22]. Available from: https://covid19.who.int

[4] Yuki K, Fujiogi M, Koutsogiannaki S. COVID-19 pathophysiology: A review. Clin Immunol Orlando Fla [Internet]. 2020 Jun [cited 2020 Nov 24];215:108427. Available from: https://www.ncbi.nlm.nih.gov/pmc/ar ticles/PMC7169933/

[5] Ngai JC, Ko FW, Ng SS, To K-W, Tong M, Hui DS. The long-term impact of severe acute respiratory syndrome on pulmonary function, exercise capacity and health status. Respirol Carlton Vic. 2010 Apr;15(3):543-50.

[6] Batawi S, Tarazan N, Al-Raddadi R, Al Qasim E, Sindi A, AL Johni S, et al. Quality of life reported by survivors after hospitalization for Middle East respiratory syndrome (MERS). Health Qual Life Outcomes [Internet]. 2019 Jun 11 [cited 2020 Dec 18];17(1):101. Available from: https://doi.org/10.1186/s12955-019$1165-2$ 
[7] Rimmer A. Covid-19: Impact of long term symptoms will be profound, warns BMA. BMJ [Internet]. 2020 Aug 13 [cited 2020 Dec 17];370:m3218. Available from: https://www.bmj.com/content/370/b mj.m3218

[8] Azer SA. COVID-19: pathophysiology, diagnosis, complications and investigational therapeutics. New Microbes New Infect [Internet]. 2020 Sep 1 [cited 2020 Nov 24];37:100738. Available from:

http://www.sciencedirect.com/scienc e/article/pii/S2052297520300901

[9] CDC. Coronavirus Disease 2019 (COVID-19) [Internet]. Centers for Disease Control and Prevention. 2020 [cited 2020 Nov 25]. Available from:

https://www.cdc.gov/coronavirus/20

19-ncov/hcp/clinical-guidancemanagement-patients.html

[10] DushyantBawiskar, Pratik Phansopkar, Ayurva Vilas Gotmare. COVID-19 Facets: Pandemics, Curse and Humanity. Int J Res Pharm Sci. 2020 Aug 6;11(SPL1):385-90.

[11] Scavone C, Brusco S, Bertini M, Sportiello L, Rafaniello C, Zoccoli $\mathrm{A}$, et al. Current pharmacological treatments for COVID-19: What's next? $\mathrm{Br} \mathrm{J}$ Pharmacol [Internet]. 2020 May 15 [cited 2020 Nov 24]; Available from: https://www.ncbi.nlm.nih.gov/pmc/ar ticles/PMC7264618/

[12] Wang TJ, Chau B, Lui M, Lam G-T, Lin N, Humbert S. PM\&R and Pulmonary Rehabilitation for COVID-19. Am J Phys Med Rehabil [Internet]. 2020 Jun 11 [cited 2020 Nov 24]; Available from: https://www.ncbi.nlm.nih.gov/pmc/ar ticles/PMC7315835/

[13] Halaris A. Inflammation-Associated Co-morbidity Between Depression and Cardiovascular Disease. Curr
Top Behav Neurosci. 2017;31:4570.

[14] Callender LA, Curran M, Bates SM, Mairesse M, Weigandt J, Betts CJ. The Impact of Pre-existing Comorbidities and Therapeutic Interventions on COVID-19. Front Immunol. 2020;11:1991.

[15] Allam M, Cai S, Ganesh S, Venkatesan M, Doodhwala S, Song $\mathrm{Z}$, et al. COVID-19 Diagnostics, Tools, and Prevention. Diagnostics [Internet]. 2020 Jun [cited 2020 Dec 16];10(6):409. Available from: https://www.mdpi.com/20754418/10/6/409

[16] Butler MJ, Barrientos RM. The impact of nutrition on COVID-19 susceptibility and long-term consequences. Brain Behav Immun [Internet]. $2020 \mathrm{Jul}$ [cited $2020 \mathrm{Dec}$ 10];87:53-4. Available from: https://www.ncbi.nlm.nih.gov/pmc/ar ticles/PMC7165103/

[17] Aktas B, Aslim B. Gut-lung axis and dysbiosis in COVID-19. Turk J Biol Turk Biyol Derg. 2020;44(3):26572.

[18] Parveen, S., and S. Jain. "Pathophysiologic Enigma of COVID-19 Pandemic with Clinical Correlates." International Journal of Current Research and Review 12, no. 13 (2020): 33-37. https://doi.org/10.31782/IJCRR.2020 .12136.

[19] Chakole, S., and V. Jaiswal. "A Review Paper on Pandemic COVID19." International Journal of Research in Pharmaceutical Sciences 11, no. Special Issue 1 (2020): 99499.

https://doi.org/10.26452/ijrps.v11iSP L1.3404.

[20] Chandankhede, K.J., and R.K. Chandankhede. "Pandemic Disease and Infectious Disease in Ayurveda with Special Reference to Covid-19." International Journal of Research in 
Pharmaceutical Sciences 11, no. Special Issue 1 (2020): 292-96. https://doi.org/10.26452/ijrps.v11iSP L1.2715.

[21] Chaple, J.N. "Ayurveda and Vyadhikshamatwa (Immunity) during COVID 19." International Journal of Research in Pharmaceutical Sciences 11, no. Special Issue 1 (2020): 1351-55. https://doi.org/10.26452/ijrps.v11iSP L1.3639.

[22] Chaudhari, B.V., and P.P. Chawle. "Life Lessons of the Pandemic "COVID-19"." International Journal of Research in Pharmaceutical Sciences 11, no. Special Issue 1 (2020): 469-71. https://doi.org/10.26452/ijrps.v11iSP L1.2814.

[23] Juneja, S., S. Dangore-Khasbage, and R.R. Bhowate. "Role of Vitamin $\mathrm{d}$ in Prevention of Corona Virus Infection (Covid-19).” International Journal of Research in Pharmaceutical Sciences 11, no. Special Issue 1 (2020): 407-10. https://doi.org/10.26452/ijrps.v11iSP L1.2737.

[24] Khan, S., S. Quazi, and M. Kaple. "The Demographical and Epidemiological Profile of
Coronavirus Disease 2019 (Covid19)- A Review." Journal of Critical Reviews 7, no. 10 (2020): 4-8. https://doi.org/10.31838/jcr.07.10.02.

[25] Kothari, L., S. Wadatkar, R. Taori, P. Bajaj, and D. Agrawal. "Coronavirus: Towards Controlling of the Pandemic-Indian Scenario." International Journal of Research in Pharmaceutical Sciences 11, no. Special Issue 1 (2020): 462-68. https://doi.org/10.26452/ijrps.v11iSP L1.2813.

[26] Lohiya, S.B., S. Damke, and R. Chaudhary. "Coronavirus Disease (COVID) 2019 in Children - A Short Review." International Journal of Current Research and Review 12, no. 17 (2020): 172-77. https://doi.org/10.31782/IJCRR.2020 .121726.

[27] Sonone, A., A. Hande, M. Gawande, and S. Patil. "Sickle Cell Individuals Are Less Vulnerable for Corona Virus Disease 2019-an Enigma." International Journal of Research in Pharmaceutical Sciences 11, no. Special Issue 1 (2020): 1015-17. https://doi.org/10.26452/ijrps.v11iSP L1.3427. 